\title{
Glutamate microinjection into the hypothalamic paraventricular nucleus attenuates ulcerative colitis in rats
}

\author{
Ting-ting $\mathrm{LI}^{1,2}$, Jian-fu ZHANG ${ }^{1,2, *}$, Su-juan FEI ${ }^{1, *}$, Sheng-ping ZHU ${ }^{1,2}$, Jin-zhou ZHU ${ }^{1,2}$, Xiao QIAO ${ }^{1,2}$, Zhang-bo LIU ${ }^{1,2}$ \\ ${ }^{1}$ Department of Gastroenterology, The Affiliated Hospital of Xuzhou Medical College, Xuzhou 221002, China; ${ }^{2}$ Department of Physiol- \\ ogy, Xuzhou Medical College, Xuzhou 221002, China
}

\begin{abstract}
Aim: To investigate the effects of glutamate microinjection into hypothalamic paraventricular nucleus (PVN) on ulcerative colitis (UC) in rats and to explore the relevant mechanisms.

Methods: 2,4,6-Trinitrobenzenesulfonic acid (100 mg/kg in 50\% ethanol) was instilled into the colon of adult male SD rats to induce UC. A colonic damage score (CDS) was used to indicate the severity of the colonic mucosal damage. The pathological changes in the colonic mucosa were evaluated using immunohistochemistry, Western blotting, biochemical analyses or ELISA. Ten minutes before UC induction, drugs were microinjected into the relevant nuclei in rat brain to produce chemical stimulation or chemical lesion.

Results: Microinjection of glutamate (3, 6 and $12 \mu \mathrm{g})$ into the PVN dose-dependently decreased the CDS in UC rats. This protective effect was eliminated after kainic acid $(0.3 \mu \mathrm{g})$ was microinjected into PVN or into the nucleus tractus solitarius (NTS) that caused chemical lesion of these nuclei. This protective effect was also prevented when the AVP-V ${ }_{1}$ receptor antagonist DPVDAV (200 ng) was microinjected into the NTS. The discharge frequency of the vagus was markedly decreased following microinjection of glutamate into the PVN. Microinjection of glutamate into the PVN in UC rats significantly increased the cell proliferation and anti-oxidant levels, and decreased the apoptosis and Bax and caspase 3 expression levels and reduced the pro-inflammatory factors in the colonic mucosa. Conclusion: The activation of hypothalamic PVN exerts protective effects against UC, which is mediated by the NTS and vagus. The effects may be achieved via anti-oxidative, anti-apoptotic, and anti-inflammatory factors.
\end{abstract}

Keywords: ulcerative colitis; 2,4,6-trinitrobenzenesulfonic acid; glutamate; kainic acid; arginine vasopressin; hypothalamus; paraventricular nucleus; nucleus tractus solitarius; vagus

Acta Pharmacologica Sinica (2014) 35: 185-194; doi: 10.1038/aps.2013.140; published online 23 Dec 2013

\section{Introduction}

Ulcerative colitis (UC) belongs to the spectrum of inflammatory bowel diseases (IBD), and refers to a chronic, relapsing and nonspecific inflammation of the colon and rectal mucosa. Long-standing UC can result in fibrosis, polyp formation and carcinogenesis in the colon. The prevalence of UC is continuously increasing ${ }^{[1]}$. However, our understanding of the pathogenesis of UC is incomplete. In the past decade, some advancements have been achieved in our understanding of the role of environmental factors ${ }^{[2]}$. Enteric microflora, genetic and immune factors have been implicated in the pathogenesis of $\mathrm{UC}^{[3-7]}$. Barbara et al advanced a challenging hypothesis that human colitis may be caused by neurogenic inflamma-

\footnotetext{
* To whom correspondence should be addressed.

E-mail jfzhang@xzmc.edu.cn (Jian-fu ZHANG); xzxhbyjs@xzmc.edu.cn (Su-juan FEI)

Received 2013-04-15 Accepted 2013-08-28
}

tion in the gut ${ }^{[8]}$. Recently, Lin et al provided direct evidence in support of this hypothesis and revealed that rat colitis can be induced directly by substance $P(S P)$ stimulation of central neurokinin-1 receptor (NK1-R) in the lumbar spine. The authors also showed that migration inhibitory factor (MIF) activity and expression were increased in experimental colitis induced by dinitrochlorobenzene (DNCB), and that the sympathetic nerve could inhibit MIF activity in colitis ${ }^{[9]}$. Ji et al observed that excessive activation of endogenous acetylcholine (ACh) may be one of the factors aggravating UC pathology and MIF pro-inflammatory cytokine expression/release in DNCB-induced colitis ${ }^{[10]}$. These results suggested that both the peripheral and central nervous systems were involved in experimental colitis. Nevertheless, little is known about the systemic regulation of $\mathrm{UC}$, and the role of the relevant central nuclei in UC.

In the hypothalamus, the PVN is an important and complex nucleus. It is a site of coordination for the neuroendocrine, 
immune, autonomic, and behavioral responses to stress. It contains many neurotransmitters and neuropeptides such as arginine vasopressin (AVP), neurotensin (NT), neuropeptide $Y$ (NPY), cholecystokinin (CCK), oxytocin (OXT), and corticotropin-releasing factor (CRF). AVP may influence cardiovascular-related functions and help to regulate pain and stress. The PVN has complex connections with other brain areas, receiving various information inputs and projecting directly to the brainstem, cerebellum, spinal cord, and the median eminencopituitary stalk from its parvocellular subdivision. It also connects to the neurohypophysis from its magnocellular subdivision $^{[11]}$. Previous anatomical studies have demonstrated direct bidirectional connections between the PVN, NTS, and DVC (dorsal vagal complex) ${ }^{[12-14]}$. Vasopressin neurons in the PVN, particularly its parvocellular sub-nuclei, innervate the NTS. The fiber tracts descending from the PVN transport AVP to the NTS ${ }^{[15,16]}$. In situ hybridization studies and autoradiographic binding assays have demonstrated the presence of AVP $V_{1}$-receptor mRNA and dense $V_{1}$-receptors in the NTS ${ }^{[17]}$.

Our previous studies have demonstrated that the PVN and NTS are important brain sites for regulating the development of gastric ischemia-reperfusion injury (GI-RI) and stress gastric mucosal damage (SGMD). Either electrical or chemical stimulation of the PVN can attenuate GI-RI, but markedly aggravate SGMD. The electrolytic ablation and chemical ablation of the NTS can abolish the protective effect of PVN stimulation on GI-RI, indicating that the NTS takes part in the modulation of GI-RI by the PVN ${ }^{[18]}$.

Efferent vagal fibers innervating the gut originate from the $\mathrm{DVC}^{[19,20]}$. A literature review demonstrated that stimulating the PVN influenced the activity of vagal efferent fibers. PVN stimulation also produced orthodromic inhibitory impulses in the NTS and DMNV (dorsal motor nucleus of the vagus), which would in turn decrease vagal efferent activity ${ }^{[21]}$.

Functionally, the PVN is a higher center controlling the activities of the autonomic nervous system in the mammalian brain. The PVN exerts profound effects on gastrointestinal function $^{[15]}$. The PVN, NTS, and the vagal fibers are important structures in the regulation of gastrointestinal function. A previous study indicated that an increase in the expression of corticotropin-releasing factor (CRF) mRNA in the hypothalamic PVN and the amygdala were observed during acute colitis, and the effect in the PVN maintained following recovery ${ }^{[22]}$.

The aim of the present study was to investigate the mechanisms and nervous pathway underlying the protective effect of chemical stimulation of the PVN against UC. The experiments were performed on a UC model established in rats. We demonstrated that the PVN participates in the regulation of UC, and that the NTS and vagus might exert critical roles in regulating several anti-oxidation, anti-apoptosis and antiinflammation factors that mediate the protective effect of the PVN.

\section{Materials and methods} Animals

Adult male Sprague-Dawley rats were obtained from the
Experimental Animal Center of Xuzhou Medical College, Xuzhou, China (Certificate No: SYXK (SU) 2002-0038). The animals weighing 200-230 g were housed in wire mesh cages under a controlled condition (temperature $23 \pm 1^{\circ} \mathrm{C}$, relative humidity $65 \% \pm 5 \%, 12 \mathrm{~h}$ light/dark cycle) and given free access to standard laboratory food and water. The experiments were conducted under National Institute of Health Guide for the Care and Use of Laboratory Animals (USA). Prior to the experiments, all rats were kept fasting for $24 \mathrm{~h}$, but allowed free access to water.

All animal experiments were approved by the Committee on Research Animal Care and Use of the Xuzhou Medical College.

\section{Reagents}

2,4,6-Trinitrobenzene sulfonic acid (TNBS), glutamate, kainic acid (KA), the glutamate receptor antagonist kynurenic acid (KYNA), and the AVP- $\mathrm{V}_{1}$ receptor antagonist [Deamino-pen ${ }^{1}$, $\mathrm{val}^{4}, \mathrm{D}-\mathrm{Arg}^{8}$ ]-vasopressin (DPVDAV) were obtained from Sigma-Aldrich (St Louis, MO, USA). The SABC immunohistochemistry detection kit, BCIP/NBT assay kit, anti-Bcl-2 polyclonal antibody, anti-Bax polyclonal antibody and anticaspase-3 polyclonal antibody were purchased from Boster Bio-engineering (Wuhan, China). The anti-rat PCNA polyclonal antibody was obtained from Santa Cruz Biotechnology (Santa Cruz, CA, USA). Malondialdehyde (MDA) and superoxide dismutase (SOD) assay kits were obtained from Nanjing Jiancheng Bioengineering (Nanjing, China). The enzymelinked immunosorbent assay (ELISA) kits were obtained from Xitang Biotech Co (Shanghai, China).

\section{Experimental groupings}

The rats were divided into different groups at random $(n=6$ per group).

The control groups included: a normal group; a UC model group (TNBS $100 \mathrm{mg} / \mathrm{kg}$ in a vehicle of $50 \%$ ethanol $(v / v)$ was instilled into the colon); and a vehicle group $(0.9 \%$ saline 0.3 $\mu \mathrm{L}$ was microinjected into $\mathrm{PVN}+\mathrm{UC}$ ).

The experimental groups included: chemical stimulation of the PVN (glutamate 3, 6, $12 \mu \mathrm{g}$ ) $+\mathrm{UC}$; chemical ablation of the PVN+UC; chemical ablation of the PVN+chemical stimulation of the PVN (12 $\mu$ g glutamate)+UC; KYNA microinjected into the PVN+chemical stimulation of the PVN $(12 \mu \mathrm{g}$ glutamate)+UC; KYNA microinjected into the PVN+vehicle microinjected into the PVN+UC; vehicle microinjected into the NTS+chemical stimulation of the PVN (12 $\mu$ g glutamate)+UC; chemical ablation of the NTS+chemical stimulation of the PVN (12 $\mu$ g glutamate)+UC; DPVDAV microinjected into the NTS +chemical stimulation of the PVN (12 $\mu$ g glutamate)+UC; and DPVDAV microinjected into the NTS+vehicle microinjected into the PVN+UC.

\section{Orientations of brain nuclei}

The rats were anesthetized with chloral hydrate $(400 \mathrm{mg} / \mathrm{kg})$ by intraperitoneal injection and subsequently fixed onto a stereotaxic apparatus. The scalp was incised, and then a hole 
with a diameter of $0.5 \mathrm{~mm}$ was drilled in the cranium dorsal to the target site. The location of the PVN and NTS were obtained according to the rat brain stereotaxic coordinates ${ }^{[23]}$. The PVN was located at AP $1.5 \mathrm{~mm}$, LR $0.4 \mathrm{~mm}, \mathrm{H}$ 7.7-7.8 mm and the NTS at AP $12.9 \mathrm{~mm}, \mathrm{LR} 0.7 \mathrm{~mm}, \mathrm{H} 7.8 \mathrm{~mm}$. The incisor bar was positioned $3.3 \mathrm{~mm}$ below the center of the aural bars.

\section{Chemical stimulation or chemical destruction of brain nuclei}

To provide chemical stimulation of the PVN, three different doses of glutamate $(3,6$, and $12 \mu \mathrm{g}$ in a volume of $0.3 \mu \mathrm{L} 0.9 \%$ saline) were microinjected into the PVN via a cannula connected to a micro-syringe with a polyethylene tube $10 \mathrm{~min}$ prior to the induction of UC. The injection lasted for $2 \mathrm{~min}$ and the injection cannula was left in place for an additional 5 min to prevent backflow ${ }^{[24]}$. When the same brain nuclei was injected of two different drugs, the interval is $7 \mathrm{~min}$. Similarly, the glutamate receptor antagonist, KYNA $(3.15 \mu \mathrm{g}$ in a volume of $0.3 \mu \mathrm{L} 0.9 \%$ saline) was injected into the PVN. The AVP receptor antagonist, DPVDAV (200 ng in a volume of $0.3 \mu \mathrm{L}$ $0.9 \%$ saline) was injected into the paired $\mathrm{NTS}^{[17]}$. Chemical ablation of the PVN or NTS was performed by microinjection of kainic acid (KA, $0.3 \mu \mathrm{g}$ in a volume of $0.3 \mu \mathrm{L} 0.9 \%$ saline $)^{[11,24]}$ into the PVN or paired NTS, respectively. In the vehicle control (sham chemical stimulation or sham ablation) groups, only the vehicle $(0.3 \mu \mathrm{L} 0.9 \%$ saline $)$ was microinjected into the PVN or NTS.

In all experiments where the PVN or NTS were stimulated or ablated the drugs were given $10 \mathrm{~min}$ before the induction of UC.

To determine whether the brain sites were microinjected or ablated correctly, the colons were removed $72 \mathrm{~h}$ later and $4 \%$ neutral formaldehyde was perfused into the hearts of the rats. The brains were removed and fixed in $10 \%$ paraformaldehyde for $48 \mathrm{~h}$. Then, the frozen brains were sectioned into $50 \mu \mathrm{m}$ slices. The sections were then stained with $1 \%$ neutral red solution to identify the sites of microinjection and lesion. The data from the rats whose target sites did not correspond with the histological criteria were removed from the statistical analysis.

\section{Model preparation of UC}

Experimental UC was induced with TNBS instillation according to the method of Morris et $a l^{[25]}$. Prior to the induction of colitis, all rats were fasted for $24 \mathrm{~h}$ and were allowed free access to water. The rats were anesthetized with $10 \%$ chloral hydrate, and then a polyurethane cannula with an external diameter of $2 \mathrm{~mm}$ was inserted through the anal canal $8 \mathrm{~cm}$ into the colon. TNBS $(100 \mathrm{mg} / \mathrm{kg})$ in a vehicle of $50 \%$ ethanol $(v / v)$ was instilled into the colon through the cannula. Following the instillation, the rats were held in a head-down position for 2 min to prevent the leakage of the intra-colonic instillation $^{[26-28]}$. They were sacrificed $72 \mathrm{~h}$ after the colitis induction.

\section{Histological analysis}

After macroscopic observation, the colon tissue samples were fixed in $10 \%$ paraformaldehyde. Then, the paraffin-embedded tissue samples were sectioned into $5 \mu \mathrm{m}$-thick slices. The sections were stained with hematoxylin and eosin (H\&E) and examined by microscopy (Model IX71, Olympus, Tokyo, Japan).

\section{Macroscopic assessment of colonic damage score (CDS)}

At the end of the experiment, the distal $10 \mathrm{~cm}$ of the rat colon was removed, opened longitudinally, and washed with cold phosphate-buffered saline (PBS). The extent of macroscopic damage was assessed by a scoring system as described by Reuter et al ${ }^{[28]}$ and Strober et al ${ }^{[29]}$ with the following modifications: grade 0: no ulcer, no inflammation; grade 1: no ulcer, local hyperemia; grade 2: ulcer with no significant hyperemia and bowel wall thickening; grade 3: ulcer with one site of inflammation; grade 4: two or more sites of ulceration or inflammation; grade 5: major ulceration extending more than $1 \mathrm{~cm}$ along the length of the colon; grade 6-10: when the area of ulceration extended more than $2 \mathrm{~cm}$ along the colon, the score was increased by 1 for each additional $\mathrm{cm}$ of involvement. To assess the severity of diarrhea, the following criteria was used: grade 0: no diarrhea; grade 1: mild diarrhea; grade 2: severe diarrhea. To evaluate the presence or absence of adhesions between the colon and other organs, the scores were counted as follows: grade 0: no adhesions; grade 1: mild adhesions (colon can be easily separated from other tissue); grade 2: major adhesions (colon cannot be separated from other tissue with little effort). The total CDS represented the extent of damage to the colon, which was scored by two researchers who were blinded to the experiments to avoid bias.

\section{Measurement of discharge frequency of the vagus}

The discharge frequency of the vagus was measured according to the method described by Horn and Friedman ${ }^{[30]}$.

The rats were anesthetized and then fixed on a stereotaxic apparatus. The coordinates of the PVN and microinjection of glutamate $(12 \mu \mathrm{g}$ in a volume of $0.3 \mu \mathrm{L} 0.9 \%$ saline) were the same as those described above. The discharge frequency of the vagus was recorded for 2 3 min before and after chemical stimulation of the PVN using single-barrel glass electrodes. The discharge signals of the vagus were amplified and filtered using a preamplifier. The signals were stored in a MedLabU/4C501 biological signal acquisition system (Nanjing Meiyi Science and Technology Co, Ltd), which examined the discharge frequency of the vagus automatically. Only stable discharge was investigated.

\section{Immunohistochemistry analysis}

To evaluate proliferation of the colonic epithelium, cells undergoing proliferation were examined by immunohistochemistry for proliferating cell nuclear antigen (PCNA) using an anti-rat PCNA polyclonal antibody (Santa Cruz Biotechnology) and the immunohistochemistry two-step detection kit (Zhongshan Golden Bridge Biotech Co, Beijing, China). We chose antiPCNA antibodies (diluted to 1:100 with PBS) and the polyHRP anti-rabbit IgG as the primary and the secondary antibod- 
ies, respectively ${ }^{[31]}$. The quantitative analysis was performed blinded under a research microscope (Model IX71, Olympus, Tokyo, Japan). The number of PCNA positive cells in ten random microscopic fields was counted at $400 \times$ magnification.

\section{Western blot}

Colonic tissues were excised and stored at $-80^{\circ} \mathrm{C}$. The frozen samples were weighed and homogenized in ice-cold buffer. The sample protein concentration was determined with a BCA protein assay kit according to a previously described method $^{[32]}$. The sample proteins were separated by $10 \%$ SDSpolyacrylamide gel electrophoresis (SDS-PAGE) and electrophoretically transferred onto a nitrocellulose membrane. The membrane was then incubated with specific primary antibodies at $4{ }^{\circ} \mathrm{C}$ overnight. The anti-Bax antibody and antiBcl-2 antibody were used at a dilution of 1:500, and the anticaspase- 3 antibody and anti- $\beta$-actin antibody were used at dilutions of 1:750 and 1:2000, respectively. After washing with PBS, each blot was incubated with the anti-mouse IgG antibody at a dilution of 1:1000. The signal detection was performed using a BCIP/NBT assay kit. The blots were scanned and analyzed by Image-Pro Plus 6.0 (Media Cybernetics, Bethesda, MA, USA).

\section{Measurement of SOD activity and MDA contents}

The measurement of SOD and MDA was performed as described ${ }^{[33]}$. The protein concentrations were determined using a Coomassie brilliant blue protein assay. The SOD activity was determined spectrophotometrically at $550 \mathrm{~nm}$, using the xanthine/xanthine oxidase method. The MDA content was detected by the thiobarbituric acid reaction and was determined spectrophotometrically at $532 \mathrm{~nm}$. SOD activity and MDA contents were expressed in $\mathrm{U} / \mathrm{mg}$ and $\mathrm{nmol} / \mathrm{mg}$ of protein, respectively.

\section{Enzyme-linked immunosorbent assay}

The protein levels of TNF- $\alpha$ and IL-1 $\beta$ in colonic tissue were detected by ELISA kits (Xitang Biotech Co, Shanghai, China) according to the methods described by Tsune ${ }^{[34]}$. The protein levels of TNF- $\alpha$ and IL-1 $\beta$ were calculated from a standard curve and the results are expressed in $\mathrm{pg} / \mathrm{mg}$.

\section{Statistical analysis}

All data are expressed as the mean \pm SD. Statistical analysis was performed using GraphPad Prism 5 and SPSS 13.0 statistical software (SPSS Inc, Chicago, IL, USA). Differences between two groups were analyzed using Student's $t$-test and multiple-group analyses were made using one-way analysis of variance (ANOVA). With all analyses, $P<0.05$ was considered statistically significant.

\section{Results}

\section{Histological verification}

All target sites of microinjections or chemical lesions of the PVN and NTS were verified histologically according to Paxinos and Watson's stereotaxic atlas ${ }^{[23]}$ (Figure 1A, 1B).
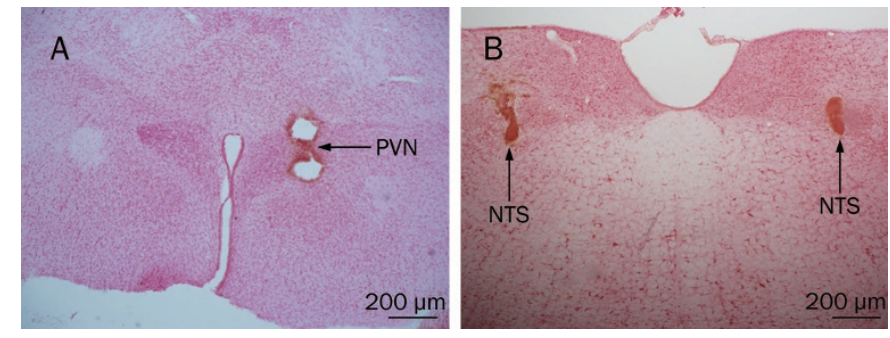

Figure 1. The target sites of PVN and NTS in the rat brain. The photomicrographs of PVN (A) and NTS (B) of microinjection or chemical ablation sites, respectively. The coronal sections were stained with $1 \%$ neutral red, showing the position of needle tip (Scale bar: $200 \mu \mathrm{m}$ ).

\section{Histological assessment of the colon}

No signs of histological damage were observed in the normal group. In both the UC and vehicle groups, severe necrosis in the colonic epithelium and destruction of tubular glands were observed. Extensive granulation tissue and a massive invasion of inflammatory cells were also apparent in the sub-mucosa. However, in the PVN group the ulceration was milder and there were fewer inflammatory cells (Figure 2).
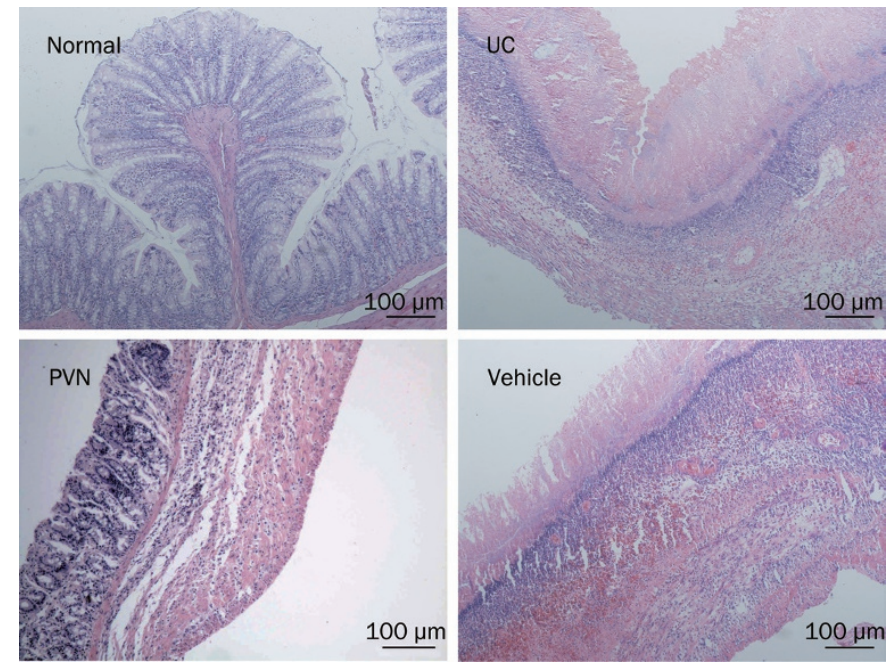

Figure 2. Histopathology of rat colon. Normal: regular colon surface epithelium; UC: necrosis at epithelium, congestion under the surface epithelium, epithelium granulation tissue, intense inflammatory cells at sub-mucosa; PVN: inflammatory cells in the mucosa and submucosa; Vehicle: severe necrosis at epithelium, intense congestion under the surface epithelium, epithelium granulation tissue and intense inflammatory cells at sub-mucosa; H\&E staining with low power $(\times 10)$ magnification.

\section{Effect of chemical stimulation or chemical ablation of the PVN} on UC

The CDS was 9.50 $\pm 1.05(n=6)$ in the UC group, and 10.53 \pm 3.32 $(n=6)$ in the vehicle group. The CDS values decreased $(7.17 \pm 0.98,5.17 \pm 0.75,3.50 \pm 1.05, n=6$, respectively) after chemical stimulation of the PVN (glutamate 3,6 , and $12 \mu \mathrm{g}$ in a vol- 
ume of $0.3 \mu \mathrm{L}$ saline) in a dose-dependent manner ( $r=-0.867$, $P<0.05)$. The CDS was $12.00 \pm 1.41(n=6)$ after chemical ablation (KA, $0.3 \mu \mathrm{g}$ in a volume of $0.3 \mu \mathrm{L} 0.9 \%$ saline) of the PVN+12 $\mu \mathrm{g}$ glutamate chemical stimulation of the PVN. A statistical analysis revealed the CDS following chemical stimulation in the PVN groups were significantly lower than both the UC group and vehicle group $(P<0.01)$ (Figure 3$)$.

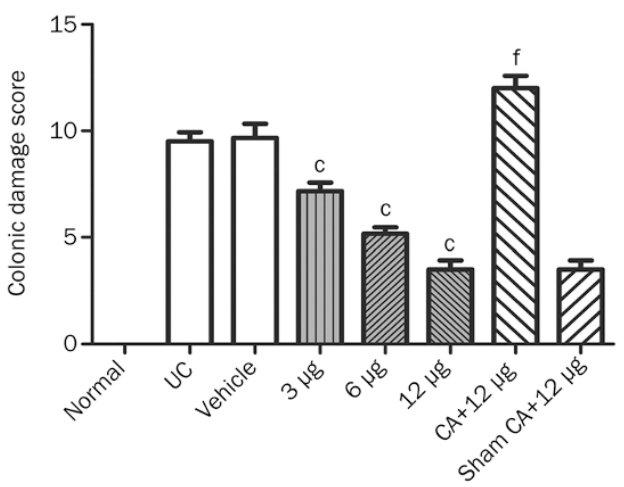

Figure 3. Effect of chemical stimulation or chemical ablation (CA) of PVN on UC in rats. Normal: normal; UC: TNBS $(100 \mathrm{mg} / \mathrm{kg})$ in a vehicle of $50 \%$ ethanol $(v / v)$ was instilled into the colon, only; Vehicle: microinjection of saline into PVN+UC; 3, 6, and $12 \mu \mathrm{g}$ : microinjection of different doses of glutamate into PVN individually+UC; $C A+12 \mu \mathrm{g}$ : chemical ablation of $P V N+12 \mu g$ glutamate stimulation of PVN+UC; Sham $C A+12 \mu g$ : sham chemical ablation of $P V N+12 \mu g$ glutamate stimulation of PVN+UC. Mean \pm SD. $n=6$. ${ }^{\circ} P<0.01$, compared with $U C$ and vehicle groups. ${ }^{f} P<0.01$, compared with the sham $C A+12 \mu$ g group. $r=-0.867, P<0.05$.

Role of glutamate receptor antagonist (KYNA) in the protective effects of chemical stimulation of the PVN on UC

The CDS was $10.00 \pm 1.26(n=6)$ in the vehicle control group and similar to that of the above group after KYNA (3.15 $\mu \mathrm{g}$ in a volume of $0.3 \mu \mathrm{L} 0.9 \%$ saline) microinjection into the PVN in conjunction with sham chemical stimulation of the PVN (CDS: $10.50 \pm 1.22, n=6)$. The CDS was $3.50 \pm 1.52(n=6)$ after vehicle was microinjected into the PVN with $12 \mu \mathrm{g}$ glutamate

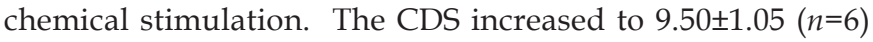
in the group in which KYNA was microinjected into the PVN in conjunction with $12 \mu \mathrm{g}$ glutamate chemical stimulation. A comparison revealed that the difference between the latter two groups was significant $(P<0.01)$ (Figure $4 \mathrm{~A})$.

The role of NTS in the protective effect of chemical stimulation of the PVN on UC

To clarify whether the NTS participates in the protective effects of chemical stimulation of the PVN during UC development, the induction of colitis and chemical ablation (KA, $0.3 \mu \mathrm{g}$ in a volume of $0.3 \mu \mathrm{L} 0.9 \%$ saline) of the NTS were performed $72 \mathrm{~h}$ before chemical stimulation of the PVN.

The CDS was 9.50 $\pm 1.05(n=6)$ in sham ablation of NTS+sham chemical stimulation of PVN+UC group, and $3.33 \pm 0.82(n=6)$ in the group of sham chemical ablation of the NTS $+12 \mu \mathrm{g}$ glutamate chemical stimulation of the PVN+UC. The CDS was $10.00 \pm 1.79(n=6)$ in the chemical ablation of the NTS+12 $\mu \mathrm{g}$ glutamate chemical stimulation of the PVN+UC group. A comparison between the first two groups and the latter two groups demonstrated a significant difference $(P<0.01$, Figure 4B).

Role of AVP-V $V_{1}$ receptor antagonist (DPVDAV) microinjected into NTS in the chemical stimulation of PVN on UC

To investigate whether the protective effect of chemical stimulation of the PVN is mediated by AVP, DPVDAV (200 ng in a volume of $0.3 \mu \mathrm{L} 0.9 \%$ saline) was microinjected into the paired NTS 10 min before chemical stimulation of the PVN. This treatment resulted in a CDS of $9.50 \pm 1.05(n=6)$. The CDS was $3.83 \pm 0.73(n=6)$ in the saline microinjected into NTS+12 $\mu \mathrm{g}$ glutamate stimulation of PVN+UC group, and the differ-
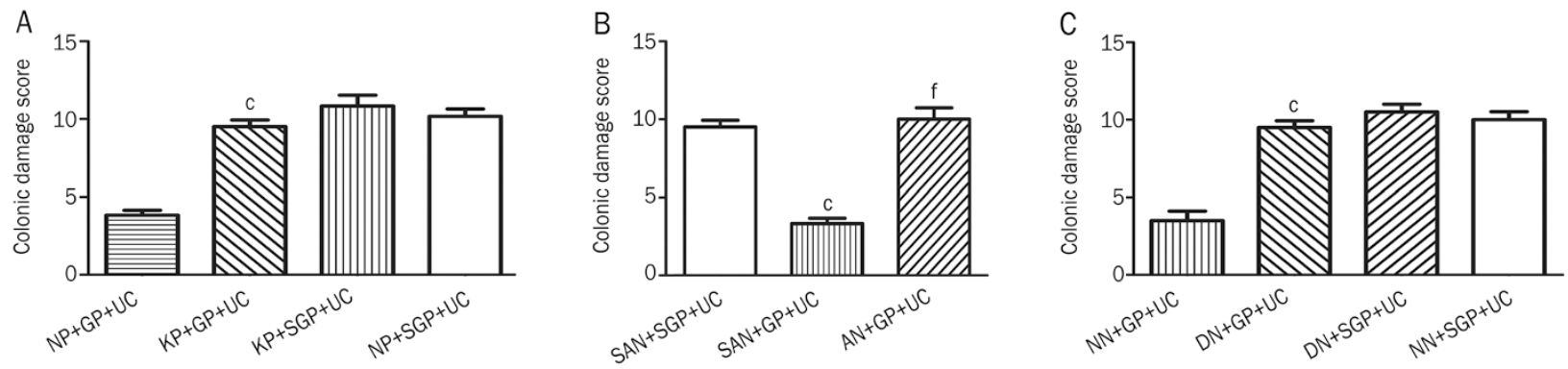

Figure 4. (A) Effect of microinjection of KYNA into PVN on UC. NP+GP+UC: saline microinjected into PVN+12 $\mu g$ glutamate stimulation of PVN+UC; KP+GP+UC: KYNA microinjected into PVN+12 $\mu$ g glutamate stimulation of PVN+UC; KP+SGP+UC: KYNA microinjected into PVN+sham stimulation of $P V N+U C$; NP+SGP+UC: saline microinjected into PVN+sham stimulation of $P V N+U C$. ${ }^{\circ} P<0.01$ compared with group NP+GP+UC. (B) Role of NTS in the protective effect of chemical stimulation of PVN on UC. SAN+SGP+UC: sham ablation of NTS+sham stimulation of PVN+UC; SAN+GP+UC: sham ablation of NTS $+12 \mu \mathrm{g}$ glutamate stimulation of PVN+UC; $A N+G P+U C$ : ablation of NTS+12 $\mu$ g glutamate stimulation of $P V N+U C$. ${ }^{c} P<0.01$ compared with group $S A N+S G P+U C ;{ }^{f} P<0.01$ compared with group $S A N+G P+U C$. (C) Effect of microinjection of DPVDAV into NTS on UC. NN+GP+UC: saline microinjected into NTS+12 $\mu$ g glutamate stimulation of PVN+UC; DN+GP+UC: DPVDAV microinjected into NTS+12 $\mu$ g glutamate stimulation of PVN+UC; DN+SGP+UC: DPVDAV microinjected into NTS+sham stimulation of PVN+UC; NN+SGP+UC: saline microinjected into NTS+sham stimulation of PVN+UC. ${ }^{\mathrm{C}} P<0.01$ compared with group $\mathrm{NN}+\mathrm{GP}+\mathrm{UC}$. 
ence between the two groups was significant $(P<0.01)$. The CDS was $10.83 \pm 1.72(n=6)$ in the DPVDAV microinjected into the NTS+sham chemical stimulation of the PVN+UC group. The CDS was $10.17 \pm 1.67(n=6)$ in vehicle microinjected into NTS+sham chemical stimulation of PVN+UC group. There was no significant difference between the latter two groups $(P>0.05)$ (Figure 4C).

\section{Effect of chemical stimulation of the PVN on the discharge frequency of the vagus}

To investigate the role of the peripheral parasympathetic pathway in the protective effect of chemical stimulation of the PVN during UC development, the discharge frequency of the vagus was recorded before and after the glutamate $(12 \mu \mathrm{g})$ chemical stimulation of the PVN. The results showed that the mean discharge frequency of the vagus decreased from $809 \pm 22.32$ $\mathrm{Hz}$ to $241 \pm 20.25 \mathrm{~Hz}(P<0.05)$ (Figure 5).

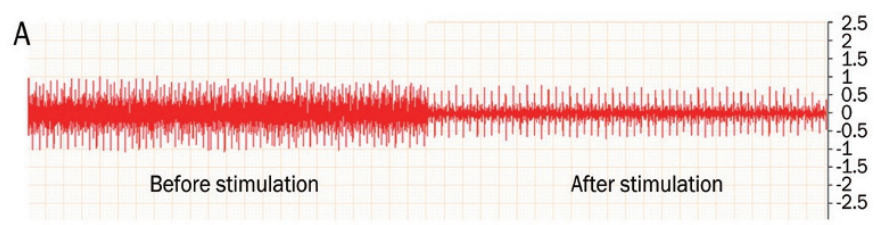

B

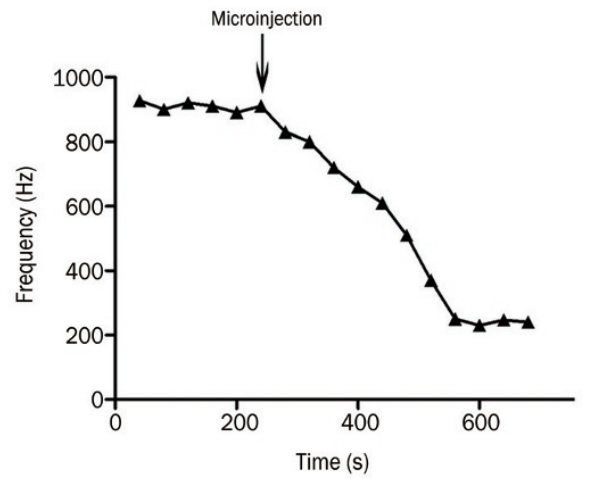

Figure 5. Effect of chemical stimulation of PVN on discharge frequency of vagus in UC rats. (A) Original record chart of vagus discharge. The horizontal (time) scale is $50 \mathrm{~ms} /$ Div and the vertical scale (the units for the voltage signal) is $0.5 \mathrm{mV} /$ Div; (B) Effect of chemical stimulation of PVN on the discharge frequency of vagus.

\section{Effect of chemical stimulation of PVN on the proliferation of} colonic epithelium

As shown in Figure 6, nuclei of PCNA-positive cells (ie, proliferative positive cells) were stained brown. In the normal group, the expression of PCNA-positive cells was abundant and the positive cell percentage was $67.00 \% \pm 4.98 \%$. The percentage of proliferative cells decreased to $23.17 \% \pm 4.45 \%$ in the UC group and $22.67 \% \pm 5.28 \%$ in the vehicle group. After glutamate was microinjected into the PVN, the percentage of PCNA-positive cells increased to $63.50 \% \pm 7.56 \%$ compared with the UC group and vehicle group $(P<0.05)$. However, there was no significant difference between the PVN group and the normal group $(P>0.05)$.
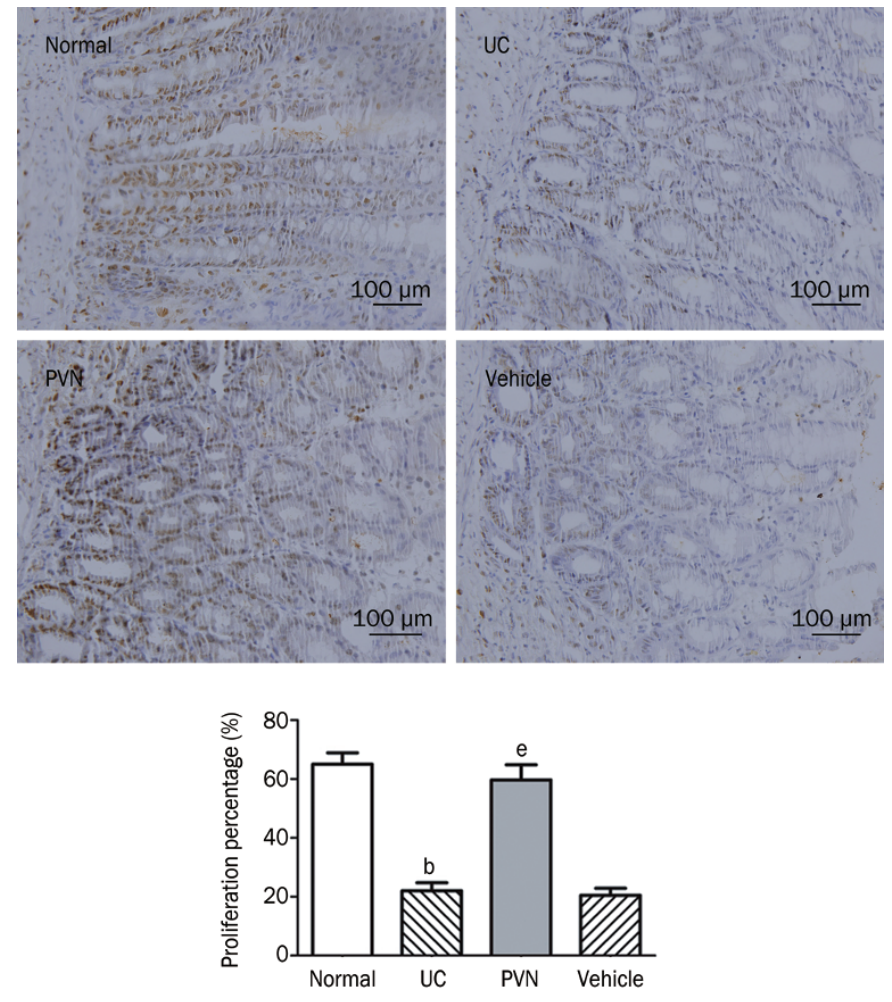

Figure 6. Effect of chemical stimulation of PVN on the proliferation of colonic epithelium in UC rats. Normal: normal; UC: TNBS $(100 \mathrm{mg} / \mathrm{kg}$ ) in a vehicle of $50 \%$ ethanol $(\mathrm{v} / \mathrm{v})$ was instilled into the colon, only; PVN: microinjection of glutamate (12 $\mu \mathrm{g})$ into PVN+UC; Vehicle: microinjection of saline into PVN+UC. Scale bar: $50 \mu \mathrm{m}$. Mean \pm SD. $n=6$. ${ }^{\mathrm{b}} P<0.05$ compared with normal group. ${ }^{e} P<0.05$ vs UC group.

Effect of chemical stimulation of PVN on the level of Bcl-2, Bax, and caspase-3

As shown in Figure 7, compared with vehicle group the protein levels of Bax and caspase- 3 were increased in the UC group. Conversely, the level of Bcl-2 was decreased $(P<0.05)$. Nevertheless, the upregulation of Bcl-2 and the downregulation of Bax and caspase- 3 were observed in the PVN group. The difference was significant compared with the UC group $(P<0.05)$.

\section{Effect of chemical stimulation of the PVN on SOD activity and MDA contents}

The enzymatic activity of SOD in the normal group reached a high level $(108.88 \pm 17.32 \mathrm{U} / \mathrm{mg})$, while it was significantly decreased in the UC group $(61.09 \pm 10.90 \mathrm{U} / \mathrm{mg})$ and the vehicle group (55.93 $\pm 11.28 \mathrm{U} / \mathrm{mg})$. Compared with the UC group, the SOD activity in the PVN group was significantly increased (100.94 $\pm 33.51 \mathrm{U} / \mathrm{mg}, P<0.01$, Figure 8A).

Low MDA contents were detected in the normal group $(3.25 \pm 1.12 \mathrm{nmol} / \mathrm{mg})$. The MDA contents were markedly elevated in the UC group $(6.26 \pm 0.79 \mathrm{nmol} / \mathrm{mg})$ compared with the normal group $(P<0.01)$. Conversely, the MDA contents were markedly decreased in the PVN group $(3.48 \pm 1.58$ 
A
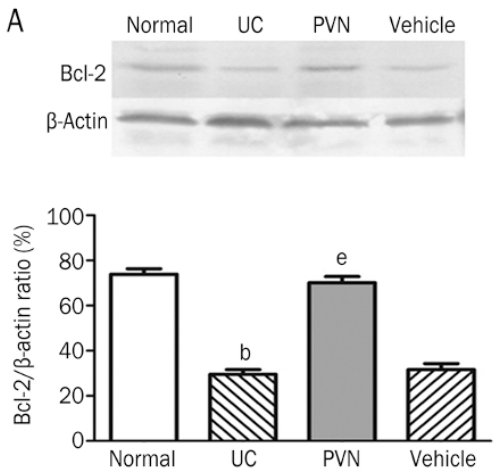

B
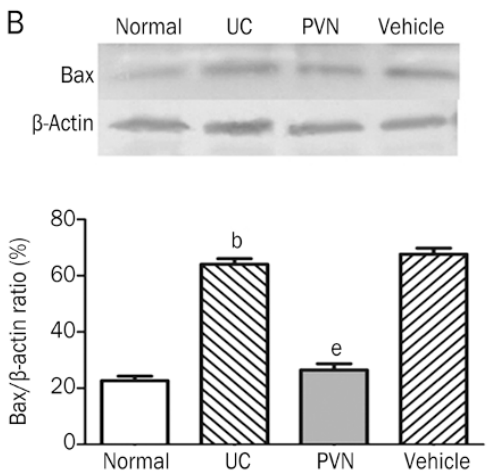
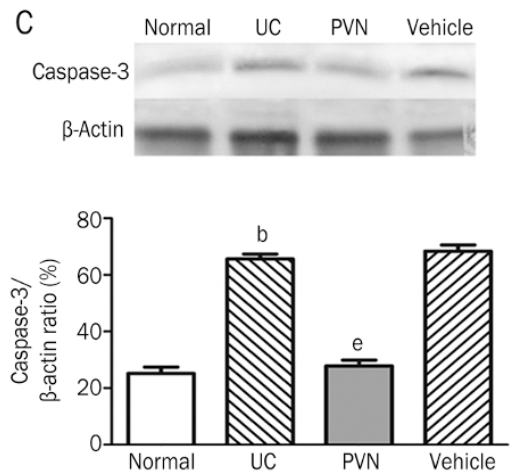

Figure 7. Effect of chemical stimulation of PVN on the expression of protein levels of Bcl-2, Bax, and caspase-3 in UC rats. (A) Bcl-2 expression; (B) Bax expression; (C) caspase-3 expression. Normal: normal; UC: TNBS (100 mg/kg) in a vehicle of $50 \%$ ethanol $(\mathrm{V} / \mathrm{V})$ was instilled into the colon, only; PVN: microinjection of $12 \mu g$ glutamate into $P V N+U C$; Vehicle: microinjection of saline into PVN+UC. Mean $\pm S D$. $n=6$. ${ }^{b} P<0.05$ compared with normal group. ${ }^{\mathrm{e}} \mathrm{P}<0.05$ vs UC group.
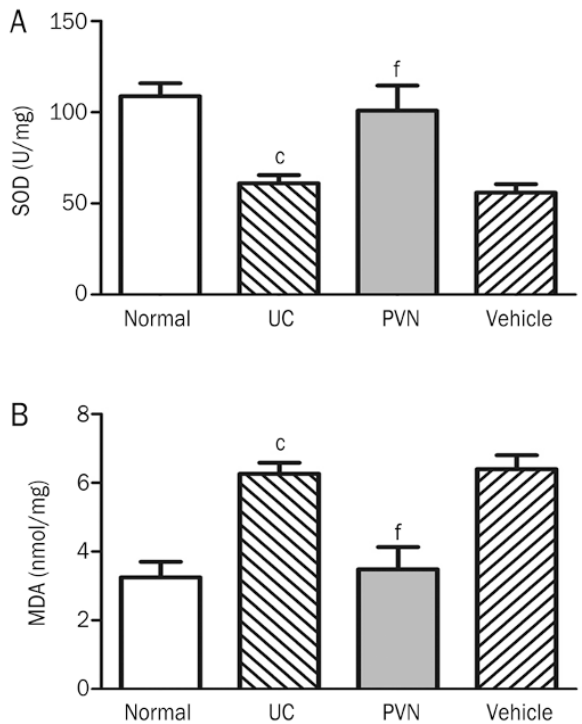

Figure 8. Effect of chemical stimulation of PVN on SOD activity and MDA contents in UC rats. (A) SOD activity; (B) MDA contents. Normal: normal; UC: TNBS $(100 \mathrm{mg} / \mathrm{kg})$ in a vehicle of $50 \%$ ethanol $(\mathrm{V} / \mathrm{v})$ was instilled into the colon, only; PVN: microinjection of $12 \mu \mathrm{g}$ glutamate into PVN+UC; Vehicle: microinjection of saline into PVN+UC. Mean \pm SD. $n=6$. ${ }^{c} P<0.01$ compared with normal group. ${ }^{f} P<0.01$ compared with UC group.

$\mathrm{nmol} / \mathrm{mg}$ ) compared with the UC group $(P<0.01)$ (Figure 8).

\section{Effect of chemical stimulation of the PVN on expression of TNF- $\alpha$ and IL-1 $\beta$ in colonic tissues}

As shown in Figure 9, the expression of TNF- $\alpha$ and IL-1 $\beta$ were both increased in the UC groups $(685.65 \pm 172.52 \mathrm{pg} / \mathrm{mg}$, $730.78 \pm 128.92 \mathrm{pg} / \mathrm{mg}$, respectively) compared with the normal control groups $(94.43 \pm 42.40 \mathrm{pg} / \mathrm{mg}, 144.8 \pm 57.18 \mathrm{pg} / \mathrm{mg}$, respectively). The differences were significant $(P<0.01)$. However, the TNF- $\alpha$ and IL-1 $\beta$ contents of the colonic tissues were significantly decreased in the PVN groups $(149.44 \pm 58.72 \mathrm{pg} /$ $\mathrm{mg}, 208.38 \pm 107.18 \mathrm{pg} / \mathrm{mg}$, respectively) compared with the UC groups $(P<0.01)$.
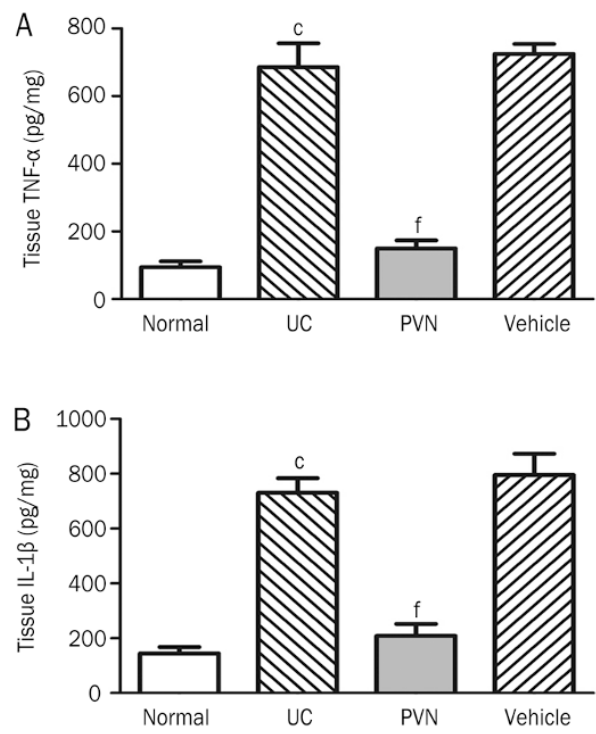

Figure 9. Effect of chemical stimulation of PVN on expression of protein levels of TNF- $\alpha$ and IL-1 $\beta$ in the colonic tissues in UC rats. (A) TNF- $\alpha$ expression; (B) IL-1 $\beta$ expression; Normal: normal; UC: TNBS (100 mg/kg) in a vehicle of $50 \%$ ethanol $(\mathrm{v} / \mathrm{v})$ was instilled into the colon, only; PVN: microinjection of $12 \mu \mathrm{g}$ glutamate into $\mathrm{PVN}+\mathrm{UC}$; Vehicle: microinjection of saline into $P V N+U C$. Mean \pm SD. $n=6$. ${ }^{c} P<0.01$ compared with normal group. ${ }^{f} P<0.01$ compared with UC group.

\section{Discussion}

The PVN is a nervous nucleus that is complex in both structure and function. It is an important brain site in regulating the development of SGMD and GI-RI. The PVN also regulates classical neurotransmitters such as ACh, NE, 5-HT. Additionally, the PVN controls the parasympathetic and sympathetic nervous systems and the three endocrine glands (thyroid, adrenal and gonad ${ }^{[2,35]}$. The PVN is also involved in TNBSinduced colitis ${ }^{[19,22]}$. In the present research, we produced an acute colitis model using TNBS $(100 \mathrm{mg} / \mathrm{kg})$ and $50 \%$ ethanol. We investigated whether the PVN plays an important role in 
the regulation of $\mathrm{UC}$ and the possible mechanisms.

In our study, different doses of glutamate microinjected into the PVN markedly attenuated UC in a dose-dependent manner. This protective effect was abolished by chemical ablation of the PVN. These results imply that the protective effect is due to the excitation of PVN neurons, not the crossing nerve fibers passing the PVN or a spread of the stimulating effect.

In situ hybridization experiments have shown that metabotropic glutamate receptor subunits and all subtypes of the ionotropic GluR mRNAs were localized in the $\mathrm{PVN}^{[36,37]}$. The protective effect was abolished after pretreatment when a glutamate receptor antagonist, KYNA, was microinjected into the PVN. The results suggest that the effect of chemical stimulation of the PVN neurons was mediated by glutamate receptors.

Anatomical evidence has demonstrated that between the PVN neurons and the lower brainstem and spinal cord there are complex connections, including descending projections from the PVN to the NTS, DVC, pituitary, and the intermediolateral cell column of the spinal cord ${ }^{[12]}$. Our results showed that when the NTS was chemically destroyed bilaterally, the protective effect of the PVN against UC was abolished. This result indicates that the NTS is an intermediary link or an important central nucleus in the regulatory mechanism of PVN for UC. The PVN might exert its complex modulation via its neural projections in the NTS region ${ }^{[38]}$. Hegarty et al demonstrated that the NTS has a high density of AVP-V receptors and is innervated by vasopressinergic fibers originating in the parvocellular PVN ${ }^{[17]}$. In our study, we observed that the protective effect was abolished by microinjection of the AVP-V $V_{1}$ receptor antagonist DPVDAV into the NTS. The results indicate that the $A V P-V_{1}$ receptors play an important role in the regulatory mechanism of the PVN for UC. These results are consistent with our previous studies ${ }^{[18]}$.

Based on our data we inferred that the protective effect of the PVN on UC might be mediated by activation of AVP-ergic neurons in the PVN. These neurons release AVP from the descending projection fibers and activate the AVP- $V_{1}$ receptors in the NTS neurons.

Additional data also revealed that electrical or chemical stimulation of the PVN could inhibit the excitability of DVC, and decrease the descending efferent impulse from the vagus $^{[39]}$. As a result, the secretion of ACh was reduced and colonic mucosal damage was alleviated through a 'nicotinic anti-inflammatory pathway' dependent on the a7-nicotinic acetylcholine receptor $(\mathrm{a} 7 \mathrm{nAChR})^{[40-42]}$. Our research showed that the discharge frequency of the vagus was decreased after chemical stimulation of the PVN, indicating that the vagus pathway played a critical role in the protective effect.

These results implied that the chemical stimulation of PVN may have a protective effect against UC via a mechanism mediated by the NTS and vagus. ACh may be involved in the regulatory mechanism.

The injuries caused by UC are regulated not only by the CNS but also by a complex pathological process. It is essential to keep a balance between proliferation and apoptosis of colonic epithelium. Bcl-2, Bax, and caspase-3 are considered to be the key factors in the regulation of cell apoptosis ${ }^{[43]}$. The Bcl-2 protein mainly inhibits cellular apoptosis and facilitates cellular survival and differentiation. The overexpression of Bax and caspase-3 proteins induces cellular apoptosis and inhibits the anti-apoptotic effect of Bcl- $2^{[44]}$. Our study indicated that chemical stimulation of the PVN can promote the proliferation of the colonic epithelium by upregulating Bcl-2 protein expression and downregulating both Bax and caspase-3 protein expression. These results demonstrated that the chemical stimulation of the PVN could effectively attenuate TNBS induced colitis by controlling the anti-apoptotic pathway in rats.

Previous studies have shown that reactive oxygen species (ROS) are important factors induced during colonic damage. The ROS impair the integrity of the intestinal epithelial cells and increase the intestinal mucosal permeability, which subsequently attenuates the barrier function and host defense to exogenous bacteria and microorganisms ${ }^{[45]}$. MDA and SOD are regarded as the oxidative/anti-oxidative index. In this study, we observed that MDA content was markedly decreased while SOD activity was elevated in colonic tissue after microinjection of glutamate into the PVN. This result indicates that the anti-oxidative effect might be involved in the regulatory mechanism of glutamate function in the PVN.

Accumulation of ROS stimulates inflammation responses and secretion of proinflammatory cytokines such as TNF- $\alpha$, IL-1 $\beta$, IL-6 in both plasma and tissues ${ }^{[46]}$. TNF- $\alpha$ and IL-1 $\beta$ are key inflammatory cytokines produced from inflammatory cells during the colonic inflammation process. Our present study showed that the expression of TNF- $\alpha$ and IL-1 $\beta$ were dramatically decreased in the colonic tissues with pretreatment of glutamate microinjected into the PVN. Our data suggest there is a protective effect of chemical stimulation of the PVN against inflammation in UC.

Our study suggests that there is a benefit of glutamate microinjection into the hypothalamic PVN in experimental colitis. The possible mechanism is thought to be mediated by the glutamate receptor on the membrane of PVN neurons. In addition, the AVP-ergic neurons are activated in the PVN, which synthesizes and releases AVP to follow the descending projection fibers from the PVN. The result is activation of the AVP- $V_{1}$ receptors in the NTS neurons. Parallel, vagal efferent activity was also decreased. The ACh release from the vagus terminals may be reduced, which may have a protective effect against the insults of UC. Moreover, expression of PCNApositive cells, the protein level of Bcl-2, and the SOD activity were obviously increased after glutamate microinjection. Conversely, MDA contents and the protein levels of Bax, caspase-3, TNF- $\alpha$, and IL-1 $\beta$ were decreased. However, further research is needed to determine whether $\mathrm{ACh}$ is involved in the regulatory mechanism.

In summary, our data demonstrated that the CNS directly participates in the regulation of UC in rats. The protective effect against the development of UC is related to the excitation of the PVN neurons. We found that microinjection of glu- 
tamate into the PVN could ameliorate TNBS-induced colitis. These results suggest a potential clinical use for the therapeutic application of PVN regulation in UC. Our results provide novel insight and improved understanding of hypothalamic function, and suggest a possible approach to UC treatment.

\section{Abbreviations}

AVP, arginine vasopressin; CDS, colonic damage score; CNS, central nervous system; DMNV, dorsal motor nucleus of the vagus; DPVDAV, [Deamino-pen ${ }^{1}, \mathrm{val}^{4}, \mathrm{D}-\mathrm{Arg}^{8}$ ]-vasopressin; DVC, dorsal vagal complex; GI-RI, gastric ischemia-reperfusion injury; IBD, inflammatory bowel disease; KA, kainic acid; KYNA, kynurenic acid; MIF, migration inhibitory factor; NTS, nucleus tractus solitarius; PVN, paraventricular nucleus; PCNA, proliferating cell nuclear antigen; SGMD, stress gastric mucosal damage; TNBS, 2,4,6-trinitrobenzenesulfonic acid; UC, ulcerative colitis.

\section{Acknowledgements}

This project was supported by grants from the National Natural Science Foundation of China (No 30570671), the Educational Science Research Foundation of Jiangsu Province (№ 10KJB310015), the Research Foundation of Xuzhou Medical College (No 07KJ58 and 07KJ34) and the Xuzhou Social Development Fund (№ XM08C062). The authors are grateful for the financial support. We thank Prof You-ting CHEN for skilled technical assistance.

\section{Author contribution}

Jian-fu ZHANG and Su-juan FEI designed the research; Tingting LI performed the research and wrote the paper; Shengping ZHU, Jin-zhou ZHU, Zhang-bo LIU, and Xiao QIAO analyzed the data.

\section{References}

1 Hanauer SB. Inflammatory bowel disease: epidemiology, pathogenesis, and therapeutic opportunities. Inflamm Bowel Dis 2006; 12 Suppl 1: S3-9.

2 Loftus EV Jr. Clinical epidemiology of inflammatory bowel disease: Incidence, prevalence, and environmental influences. Gastroenterology 2004; 126: 1504-17.

3 Mei Q, Yu JP, Xu JM, Wei W, Xiang L, Yue L. Melatonin reduces colon immunological injury in rats by regulating activity of macrophages. Acta Pharmacol Sin 2002; 23: 882-6.

4 Baumgart DC, Carding SR. Inflammatory bowel disease: cause and immunobiology. Lancet 2007; 369: 1627-40.

5 Xavier RJ, Podolsky DK. Unravelling the pathogenesis of inflammatory bowel disease. Nature 2007; 448: 427-34.

6 Krishnan K, Arnone B, Buchman A. Intestinal growth factors: potential use in the treatment of inflammatory bowel disease and their role in mucosal healing. Inflamm Bowel Dis 2011; 17: 410-22.

7 Paiotti AP, Miszputen SJ, Oshima CT, Artigiani Neto R, Ribeiro DA, Franco M. Etanercept attenuates TNBS-induced experimental colitis: role of TNF-alpha expression. J Mol Histol 2011; 42: 443-50.

8 Barbara G, De Giorgio R, Stanghellini V, Gionchetti P, Campieri M, Corinaldesi R. Relapsing ulcerative colitis after spinal cord stimulation: A case of intestinal neurogenic inflammation? Gastroenterology 1999; 117: 1256-7.
9 Lin P, Wu XY, Pan H, Jiang HJ, Mei L. Rat colitis induced by intrathecal injection of substance P. Sheng Li Xue Bao 2009; 61: 331-8.

$10 \mathrm{Ji}$ LL, Lin P, Pan H, Mei L. Effect of acetylcholine on the activity of migration inhibitory factor in mouse colitis. Chin Pharmacol Bull 2010; 26: 939-43.

11 Barcelo AC, Fillipini B, Pazo JH. Study of the neural basis of striatal modulation of the jaw-opening reflex. J Neural Transm 2010; 117: 171-81.

12 Kannan $\mathrm{H}$, Yamashita $\mathrm{H}$. Connections of neurons in the region of the nucleus tractus solitarius with the hypothalamic paraventricular nucleus: their possible involvement in neural control of the cardiovascular system in rats. Brain Res 1985; 329: 205-12.

13 Zhang X, Fogel R. Glutamate mediates an excitatory influence of the paraventricular hypothalamic nucleus on the dorsal motor nucleus of the vagus. J Neurophysiol 2002; 88: 49-63.

14 Chang HY, Mashimo H, Goyal RK. Musings on the wanderer: what's new in our understanding of vago-vagal reflex? IV. Current concepts of vagal efferent projections to the gut. Am J Physiol Gastrointest Liver Physiol 2003; 284: G357-66.

15 Flanagan LM, Dohanics J, Verbalis JG, Stricker EM. Gastric motility and food intake in rats after lesions of hypothalamic paraventricular nucleus. Am J Physiol 1992; 263: R39-44.

16 Farrell RJ, Peppercorn MA. Ulcerative colitis. Lancet 2002; 359: 331-40.

17 Hegarty AA, Felder RB. Vasopressin and $\mathrm{V}_{1}$-receptor antagonists modulate the activity of NTS neurons receiving baroreceptor input. Am J Physiol 1997; 273: R143-52.

18 Zhang JF, Zhang YM, Yan CD, Zhou XP. Neuroregulative mechanism of hypothalamic paraventricular nucleus on gastric ischemia-reperfusion injury in rats. Life Sci 2002; 71: 1501-10.

19 Kojima K, Naruse Y, lijima N, Wakabayashi N, Mitsufuji S, Ibata Y, et al. HPA-axis responses during experimental colitis in the rat. Am J Physiol Regul Integr Comp Physiol 2002; 282: R1348-55.

20 Li L, Zhang YM, Qiao WL, Wang L, Zhang JF. Effects of hypothalamic paraventricular nuclei on apoptosis and proliferation of gastric mucosal cells induced by ischemia/reperfusion in rats. World $J$ Gastroenterol 2007; 13: 874-81.

21 Zhang X, Fogel R, Renehan WE. Stimulation of the paraventricular nucleus modulates the activity of gut-sensitive neurons in the vagal complex. Am J Physiol 1999; 277: G79-90.

22 Greenwood-Van Meerveld B, Johnson AC, Schulkin J, Myers DA. Long-term expression of corticotropin-releasing factor (CRF) in the paraventricular nucleus of the hypothalamus in response to an acute colonic inflammation. Brain Res 2006; 1071: 91-6.

23 Paxinos G, Watson C. The rat brain in stereotaxic coordinates, 2nd ed. Sydney: Elsevier Academic Press; 2005.

24 Gao L, Fei SJ, Qiao WL, Zhang JF, Xing HB, Du DS. Protective effect of chemical stimulation of cerebellar fastigial nucleus on stress gastric mucosal injury in rats. Life Sci 2011; 88: 871-8.

25 Morris GP, Beck PL, Herridge MS, Depew WT, Szewczuk MR, Wallace $\mathrm{JL}$. Hapten-induced model of chronic inflammation and ulceration in the rat colon. Gastroenterology 1989; 96: 795-803.

26 Sawchenko PE, Swanson LW. Immunohistochemical identification of neurons in the paraventricular nucleus of the hypothalamus that project to the medulla or to the spinal cord in the rat. J Comp Neurol 1982; 205: 260-72.

27 Phillips PA, Abrahams JM, Kelly J, Paxinos G, Grzonka Z, Mendelsohn $\mathrm{FA}$, et al. Localization of vasopressin binding sites in rat brain by in vitro autoradiography using a radioiodinated $\mathrm{V}_{1}$ receptor antagonist. Neuroscience 1988; 27: 749-61.

28 Reuter BK, Asfaha S, Buret A, Sharkey KA, Wallace JL. Exacerbation 
of inflammation-associated colonic injury in rat through inhibition of cyclooxygenase-2. J Clin Invest 1996; 98: 2076-85.

29 Strober W, Fuss I, Mannon P. The fundamental basis of inflammatory bowel disease. J Clin Invest 2007; 117: 514-21.

30 Horn CC, Friedman MI. Thoracic cross-over pathways of the rat vagal trunks. Brain Res 2005; 1060: 153-61.

31 Zhu JZ, Fei SJ, Zhang JF, Zhu SP, Liu ZB, Li TT, et al. Muscimol microinjection into cerebellar fastigial nucleus exacerbates stressinduced gastric mucosal damage in rats. Acta Pharmacol Sin 2013; 34: 205-13.

32 Jiang W, Yang ZB, Zhou QH, Huan X, Wang L. Lipid metabolism disturbances and AMPK activation in prolonged propofol-sedated rabbits under mechanical ventilation. Acta Pharmacol Sin 2012; 33: 27-33.

33 Du DS, Ma XB, Zhang JF, Zhang YM, Zhou XY, Li Y. Cellular and molecular mechanisms of 17 beta-estradiol postconditioning protection against gastric mucosal injury induced by ischemia/reperfusion in rats. Life Sci 2010; 86: 30-8.

34 Tsune I, Ikejima K, Hirose M, Yoshikawa M, Enomoto N, Takei Y, et al. Dietary glycine prevents chemical-induced experimental colitis in the rat. Gastroenterology 2003; 125: 775-85.

35 Zhang JF, Zheng F. The role of paraventricular nucleus of hypothalamus in stress-ulcer formation in rats. Brain Res 1997; 761: 203-9.

36 Al-Ghoul WM, Meeker RB, Greenwood RS. Differential expression of five $\mathrm{N}$-methyl-D-aspartate receptor subunit mRNAs in vasopressin and oxytocin neuroendocrine cells. Brain Res Mol Brain Res 1997; 44: 262-72.

37 Mateos JM, Azkue J, Benitez R, Sarria R, Losada J, Conquet F, et al. Immunocytochemical localization of the mGluR1b metabotropic gluta- mate receptor in the rat hypothalamus. J Com Neurol 1998; 390: 225-33.

38 Zhang JF, Zhang YM, Yan CD, Zhou XP, Qi YJ. Protective effects of paraventricular nucleus stimulation and vasopressin on gastric ischemia-reperfusion injury in rats. Sheng Li Xue Bao 2002; 54: 133-8.

39 Gunion MW, Kauffman GL, Tache Y. Intrahypothalamic corticotrophinreleasing factor elevates gastric bicarbonate and inhibites stress ulcers in rats. Am J Physiol 1990; 258: G152-7.

40 Van Der Zanden EP, Boeckxstaens GE, de Jonge WJ. The vagus nerve as a modulator of intestinal inflammation. Neurogastroenterol Motil 2009; 21: 6-17.

41 Ulloa $\mathrm{L}$. The vagus nerve and the nicotinic anti-inflammatory pathway. Nat Rev Drug Discov 2005; 4: 673-84.

42 Snoek SA, Verstege MI, van der Zanden EP, Deeks N, Bulmer DC, Skynner M, et al. Selective alpha7 nicotinic acetylcholine receptor agonists worsen disease in experimental colitis. Br J Pharmacol 2010; 160: 322-33.

43 Carambula SF, Matikainen T, Lynch MP, Flavell RA, Goncalves PB, Tilly JL, et al. Caspase-3 is a pivotal mediator of apoptosis during regulation of the ovarian corpus luteum. Endocrinology 2002; 143: 1495-501.

44 Adams JM, Cory S. The Bcl-2 protein family: arbiters of cell survival. Science 1998; 281: 1322-6.

45 Liu CJ, Jin JD, Lv TD, Wu ZZ, Ha XQ. Keratinocyte growth factor gene therapy ameliorates ulcerative colitis in rats. World J Gastroenterol 2011; 17: 2632-40.

46 Neilly PJ, Gardiner KR, Kirk SJ, Jennings G, Anderson NH, Elia M, et al. Endotoxaemia and cytokine production in experimental colitis. $\mathrm{Br} J$ Surg 1995; 82: 1479-82. 